\title{
Tissue fuel and weight loss after injury
}

J. M. KINNEY, J. H. DUKE, Jr., C. L. LONG, AND F. E. GUMP

From the Department of Surgery, Columbia University College of Physicians and Surgeons, New York, USA

In physiological and metabolic studies it is common to refer to a mythical 'average' or ' $70 \mathrm{~kg}$ ' man. It is useful to consider how this average adult individual would respond to injury as judged by the literature on injury of the past decade, with particular attention to the ideas which pertain to the supposed energy and fuel demands of this individual. The most common feature of the injured person is a period of prompt weight loss, the rate of which is roughly proportional to the severity of the injury. Extra demands are placed on vital organs. Nitrogen excretion is increased, reflecting protein breakdown. These postinjury changes are consistent with the concept that injury produces large increases in the level of resting metabolism. Such increases in the demand for tissue fuel occur at a time of reduced calorie intake, hence a large weight loss is to be expected as the body consumes it own tissue for fuel. If body protein is considered to be a primary energy reserve of the body, then extra nitrogen excretion would naturally follow the breakdown of protein to meet these extra fuel needs. Several authors have suggested calorie expenditures of 5,000 to 6,000 calories per day (approximately three times normal) following a major injury such as an extensive burn (Artz and Reiss, 1957; Moore, 1959). Extreme weight loss after injury presumably reflects the loss of both protein and adipose tissue in order to meet such large energy demands. In addition to the increased oxidation of protein and fat, there is some decrease in tolerance to exogenous glucose and perhaps a tendency to hyperglycaemia. This has been termed the 'diabetes of injury' and has been interpreted as a reduction in the capacity to oxidize glucose.

Cuthbertson divided the response to injury into

'This work was supported in part by the US Army Medical Research and Development Command, contract no. DA-49-193MD-2552, and the National Institute of General Medical Sciences, grant no. GM-14546-04, and the Hartford Foundation. an 'ebb and a flow' phase (Cuthbertson, 1942). The 'ebb' period was considered the period of diminished vitality and metabolism with circulatory deficiency as its central feature and occurring immediately after the injury. The 'flow' period was considered the period of increased metabolism or 'traumatic inflammation' which was considered to begin in 24 to 48 hours after the injury and was assumed to correspond to an inflammatory defence and removal of necrotic tissue. This flow phase of convalescence was observed to be accompanied by an increase in blood sugar and body temperature, as well as increases in pulse and respiration and probably increased activity of the hypothalamic-pituitary-adrenocortical axis with depletion of body protein.

Moore (1953) subdivided the 'flow' phase of convalescence after injury into an early or catabolic phase lasting three to seven days after elective operation and a longer period after major injury and sepsis, and then a 'turning point' of a few days with a reduction in nitrogen excretion and weight loss, followed by weeks of anabolism with restoration of protein stores, adipose tissue, and general vitality. The metabolic response in the posttraumatic period is based on the type and extent of the injury and the previous health of the patient. As an approach to grading the severity of trauma, a 'scale of 10' has been proposed (Moore and Ball, 1952). The repair of a hernia would be regarded as 1 or 2 on this scale, whereas the extreme injuries such as major burns would qualify as 9 or 10. In the middle ranges would be ordinarily elective abdominal surgery, such as subtotal gastrectomy or colectomy.

\section{Weight Loss after Injury}

Mild to moderate degrees of weight loss are so common that careful efforts to monitor weight loss are often lacking in hospital care. It is 
assumed that tissue function is not restricted by mild weight loss and that the loss can be restored without difficulty as convalescence progresses. At the opposite extreme is the prompt but nonspecific worry of the clinician when faced with the patient having undergone extreme weight loss. Studley was among the first to call attention to some of the implications of weight loss in preoperative patients (Studley, 1936). In a study of 46 patients operated upon for chronic ulcer disease he found that the percentage of preoperative weight loss was the only factor that correlated with operative mortality rates. The mortality rate was $33 \%$ in those patients who had lost more than $20 \%$ of body weight before operation. In those who lost less than $20 \%$ of their normal weight the mortality was $3.5 \%$. Between the lack of concern with lesser degrees of weight loss and the worry over extreme loss is a large and ill defined range of weight loss whose development is only slowly noticed, where the composition of tissue loss is not clear, and the metabolic significance remains uncertain.

The extent of weight loss which has been reported as a result of partial starvation provides some background for considering weight loss after injury. The nutritional literature contains many reports of the weight loss of civilians, which reached $10-20 \%$ of body weight when subjected to the food restrictions of wartime. Famine conditions and wartime prison life have been reported to cause $15-30 \%$ weight loss without being lethal. The cachexia of late starvation, such as in certain concentration camp victims, was associated with the loss of 30 to $45 \%$ of body weight. Krieger (1920) attempted to show that a lethal degree of weight loss existed from starvation alone and suggested that $40 \%$ loss was lethal in acute starvation and $50 \%$ in semi-starvation. Keys and others (Keys, Brožek, Henschel, Mickelsen, and Taylor, 1950) reviewed this concept and emphasized that such figures could only represent rough approximations at best. It appears that underlying organic disease usually decreases the extent of weight loss from starvation which can be survived, and there is some reason to believe that acute surgical conditions further decrease the tolerance to prolonged weight loss.

The weight loss after injury is usually due to a combination of decreased dietary intake and a variable increase in basal energy expenditure. The extent of weight loss has been shown by many workers to be influenced by the patient's sex, body build, the preoperative nutritional status, the degree of injury, and the presence of complicating factors such as infection. Our experience with adult surgical patients suggests that loss of weight between 5 and $10 \%$ occurs after mild, uncomplicated forms of injury such as elective operation. Intermediate levels of weight loss, from 10 to $20 \%$, occur within four to six weeks after more severe injury, particularly if involving multiple fractures or major sepsis. If there is continuing inflam- mation, such as active peritonitis, draining fistulae, or invasive infection from an infected burn surface, the loss of body weight will reach 20 to $30 \%$. Severe tissue wasting will be evider unless obscured by water retention. Weight los beyond $30 \%$ represents precachexia with increas? ing trouble from weakness, decubitus ulcers, are joint contractures. Death is often associated wit bronchopneumonia.

\section{Composition of the Adult Body}

An approximate idea of the normal compositiont of the adult body is necessary to understand the weight loss which occurs after injury. Class information about the chemical composition of the human body has depended upon the analysis of postmortem tissues. In the last few decades methods have been developed which perms estimates of the body composition of the living subject. These techniques have largely been directed toward the calculation of the body content of fat or water. Fat is an anhydrous tissue with a lower density than lean tissue. Therefore, the density of the whole body can be measured by immersion (Buskirk, 1961) or by pneumatic meang in a chamber (Siri, 1961) an estimation of bod $\Phi$ fat can be made. Another method which is more feasible for the study of the ill or injured patier involves an injection of a tracer material which distributed throughout the body water and allows the calculation of body content of the giveg mater ial from dilution of the tracer(Moore, 1946 In order to convert the value for total body wate to the value of fat-free tissue in the body, the percentage of water in lean tissue must be know The studies of Pace and Rathburn (1945) have shown that fat-free tissue normally contains close to $73 \%$ water by weight. Thus the fat-free bodg weight obtained from isotope dilution can be. subtracted from total body weight to arrive at fad content. The factor of $73 \%$ water in fat-free tissue probably has some variation in disease and injury? No methods are currently available for the direct determination of the amount of protein or skeleto in the body weight (Baker, 1961). But evidenaes from many lines of study suggest that the body composition presented in Fig. 1 is a reasonable approximation of that which is present in abo average, healthy adult male weighing $70 \mathrm{~kg}$. The total mineral content of the body, largely found in the skeleton, represents 3 to $5 \%$ of the totat body weight. This amount is not only small but also relatively static when compared with the changes occurring elsewhere in the body. The remaining $95 \%$ of the body can be convenientlo regarded in two phases: the aqueous phase amounting to approximately $55 \%$, and the organiophase, amounting to approximately $40 \%$ of tota body weight. The organic and the aqueous phase of body composition will be discussed separately. but it is important to remember that the metabolf 


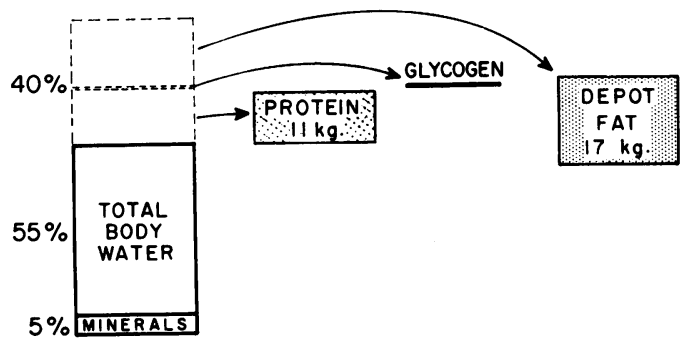

Fig. 1 The approximate proportions of aqueous and organic phases are shown for the body composition of an average $70-\mathrm{kg}$ adult male. The small fraction of body weight (3 to $5 \%$ ) shown for minerals is largely that of the skeleton.

machinery or 'body cell mass' is a combination of organic materials together with intracellular water and electrolytes. In terms of body composition the body cell mass (Moore, Olesen, McMurrey, Parker, Ball, and Boyden, 1963) appears to include tissue glycogen and a major portion, but not all, of the total body protein. Therefore it is the body cell mass which is constantly converting oxygen and foodstuffs to carbon dioxide, water, work, and heat. It seems probable that the amount of average turnover of this body cell mass bears a fundamental relationship to alveolar ventilation, cardiac output, and resting metabolicexpenditure.

Somewhat over half of the organic material in the body is shown as fat. A body fat content of $17 \mathrm{~kg}$ represents $24 \%$ of the total body weight. It is recognized that fat can vary from 10 to over $40 \%$ of total body weight. The fat content of healthy adults normally increases with age from approximately $10 \%$ at the age of 20 years to 25 or $30 \%$ at the age of 55 years. Women are usually somewhat fatter than men. Carbohydrate is present in the human body in small amounts only, approximately $300 \mathrm{~g}$ of glycogen being present in liver and muscle and in addition 10 to $20 \mathrm{~g}$ of glucose in the extracellular water. Therefore the total carbohydrate provides less than 1,500 calories and amounts to less than $1 \%$ of total body weight. A protein content of $11 \mathrm{~kg}$ in the representative adult male is an estimate based on analyses of individual tissue and calculations by difference, utilizing many human studies, of the content of body fat. The amount of skeletal material and lean tissue and perhaps a small amount of structurally important fat appear to be genetically controlled for the individual. But the total amount of fat is a variable segment of body composition, since it reflects the voluntary alterations of energy balance.

Loss of body weight following operative or physical injury is so common that the metabolic dynamics involved and the potential consequences that may ensue have failed to receive serious consideration. It was not until Cuthbertson's pioneering observation (1932) of the excessive excretion of urinary nitrogen, sulphur, and phosphorus by patients who had sustained fractures of long bones that any significant analysis of posttraumatic weight loss was attempted. When an average $70-\mathrm{kg}$ man loses $15 \mathrm{~kg}$, the various segments of bis composition do not share equally in this weight loss (Moore, McMurrey, Parker, and Magnus, 1956). The total body water shows small decreases in absolute amount, while the relative amount of water may increase. The extracellular space shrinks with acute weight loss. By contrast, chronic weight loss is associated with intracellular depletion. Acute illness and trauma are accompanied by the accumulation of water and salt. Water accumulates in excess of sodium, resulting in hypotonicity. This response is of particular importance in understanding the body composition of the non-obese patient who has lost more than $10 \%$ of his body weight from a major injury with the associated partial starvation. The principal decrease occurs in the intracellular portion of the body, mainly represented by protein and cell water, together with a significant loss of fat. The extracellular space shows a relative, or even an absolute, increase in volume. The body behaves as though protection from chronic weight loss can be provided by enlarging the extracellular space as the body cell mass shrinks. The composition of the blood volume is an excellent indicator of the change in total body composition, since the decrease of the body cell mass is reflected by a decrease in red cell volume, and the abnormal enlargement of the extracellular water is evidenced by an abnormally large plasma volume. Because these changes are in opposite directions, the total blood volume is often equal to the normal amount for this person in health.

Any metabolic behaviour which is thought to occur after injury must account for the extent of the weight loss which is commonly observed. The ideas from the literature indicate that the weight loss is explicable on the basis of injury causing a large increase in energy expenditure, and therefore body substance, particularly protein, is torn down to provide the extra fuel which is required. This formulation is based on a large volume of data about weight loss and nitrogen loss after injury which in general shows a correlation between the rates of nitrogen loss and weight loss. Maximum rates of loss of both nitrogen and total weight occur together (excluding transient diuresis), and it is rare for sustained weight gain to begin before a positive nitrogen balance has been achieved. Such observations are entirely consistent with the idea that protein serves as a major energy reserve during injury and sepsis. Thus measurements are needed to determine what are the increased calorie needs after injury or sepsis, and what calorie contribution is made by the protein breakdown which can be shown to occur. 


\section{Energy Requirements after Injury}

Because of the central role of energy requirements after injury in determining the amount of body tissue required for fuel and also the caloric contribution of tissue protein to these energy demands, our studies began with efforts to measure the resting metabolic expenditure after various forms of injury and infection. No chamber calorimeters have been designed for the direct measurement of body heat loss which would allow
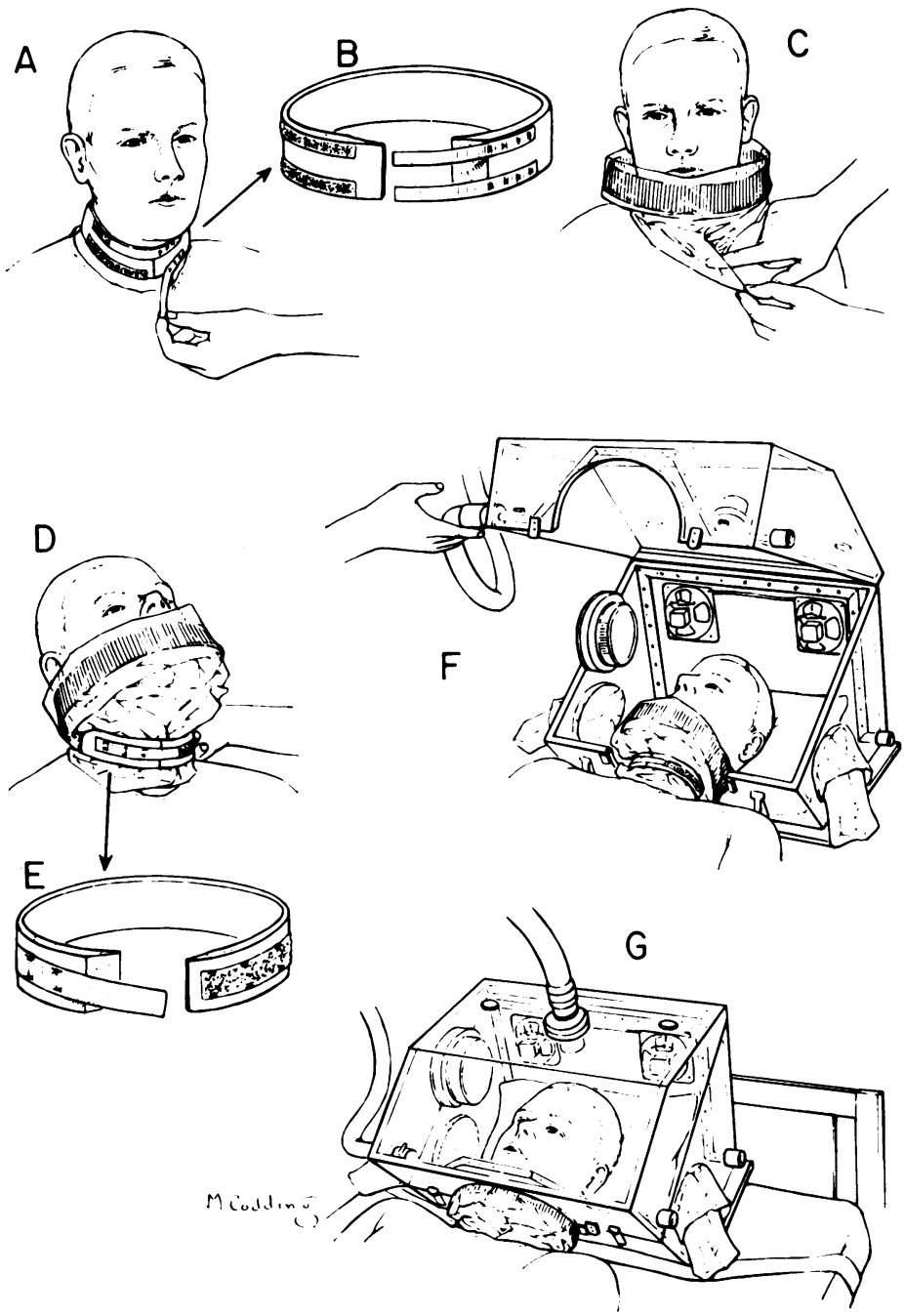

Fig. 2 Continuous measurement of gas exchange and expired radioactivity can be performed without the difficulties of a tight-fitting mask or mouthpiece, utilizing a transparent, rigid head canopy. The canopy is ventilated with air which is continuously analysed downstream with equipment located in an adjacent room. The steps involved in fitting a lightweight plastic neckseal between the patient and canopy are shown here. Reproduced with kind permission of the publisher from Cuthbertson (1932). appropriate professional care of the critically is patient. Therefore we have turned to indirect calorimetry as a way of measuring the amount and composition of each type of foodstuff beins metabolized. This involves measuring the intake: of oxygen, the output of carbon dioxide, and the excretion of nitrogen. The clinical importance of measuring metabolic expenditure under nonbasa conditions had led to efforts at simplification, bu的 the assumptions and restrictions of the modifie $\Phi^{\circ}$ methods have made them undesirable for the accurate study of acutely injured patients. Certaiff techniques require a degree of isolation of the patient which prevents close professional car $\overrightarrow{\mathrm{e}_{\text {. }}}$ while the patient is being studied. Therefore system of continuous measurement of gaos: exchange in acutely ill patients has been designee for use without a tight-fitting mask or mouthpiece्s or other attachment to the upper airway. It involves a closed system using a rigid, transparend head canopy (Fig. 2) which is practical ang comfortable for long study periods (Kinney? Morgan, Domingues, and Gildner, 1964). A lighte weight plastic neck seal provides a leak-proo connexion to the canopy, which is ventilated wit a continuous stream of conditioned air. The air leaving the canopy is passed through pipes in the wall to a gas analyzer, located in another room where flow and gas concentrations are continu ously monitored. A unique calibration syster allows routine measurements of gas exchange to be reliable within $\pm 5 \%$, and often within $\pm 3 \%$.

Experience with this equipment in the study of over 200 patients with various surgical conditions has allowed the establishment of ranges of increase in resting metabolic expenditure relative to the predicted basal metabolic expenditure of af individual of a given size, sex, and age. The norma range for average adult males is considered to be $\pm 10 \%$ of the predicted normal value from $\mathrm{BMB}$ tables, as shown in Figure 3. Uncomplicated. elective operations are followed by no significar

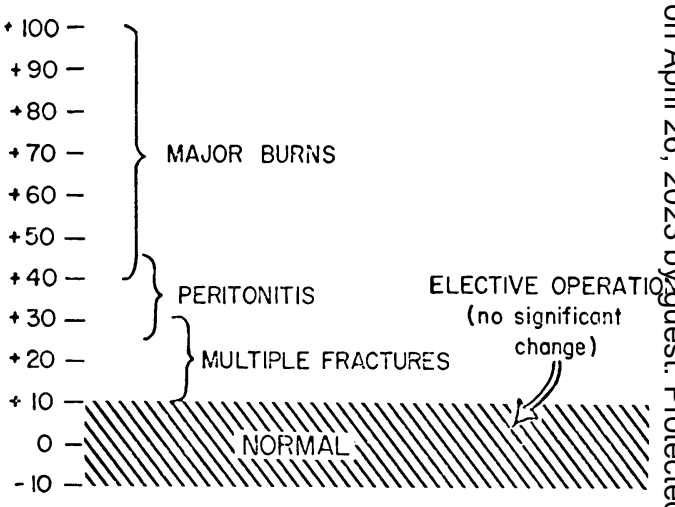

Fig. 3 The ranges of increase in resting metabolic expenditure to be seen in well nourished adult males $?$ following various forms of injury and sepsis. The response to these conditions is less in the female, in the elderly, and in the poorly nourished individual. 
Jørgenson, Broell, Long, and Kinney, 1970). Patients undergoing elective operation were similar to the normal subjects with protein supplying an average of $15 \%$ of the caloric expenditure. Protein supplied approximately $20 \%$ of calories in the tissue fuel of six patients with major trauma and sepsis, while a similar increase in nitrogen excretion of four patients with major burns averaged only $14 \%$ of the resting caloric expenditure, since the latter was elevated to an average of nearly $60 \%$. Therefore, protein (or amino acids) provides only 12 to $22 \%$ of the caloric expenditure, even in the forms of injury

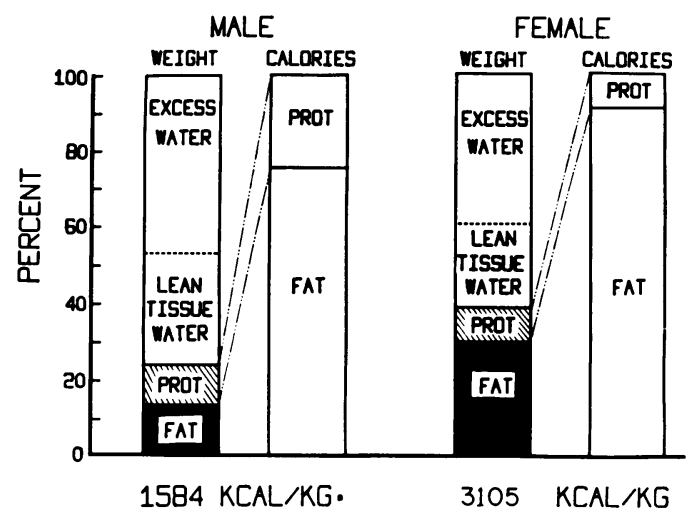

Fig. 5 The components of postoperative weight loss over 10 days are expressed as percentages of fat, protein, and water. The percentage of total calories derived from fat approximates 80 to $90 \%$ of the total despite contributing only 10 to $30 \%$ to the weight loss. Reproduced with kind permission of the publisher from Lusk (1928).

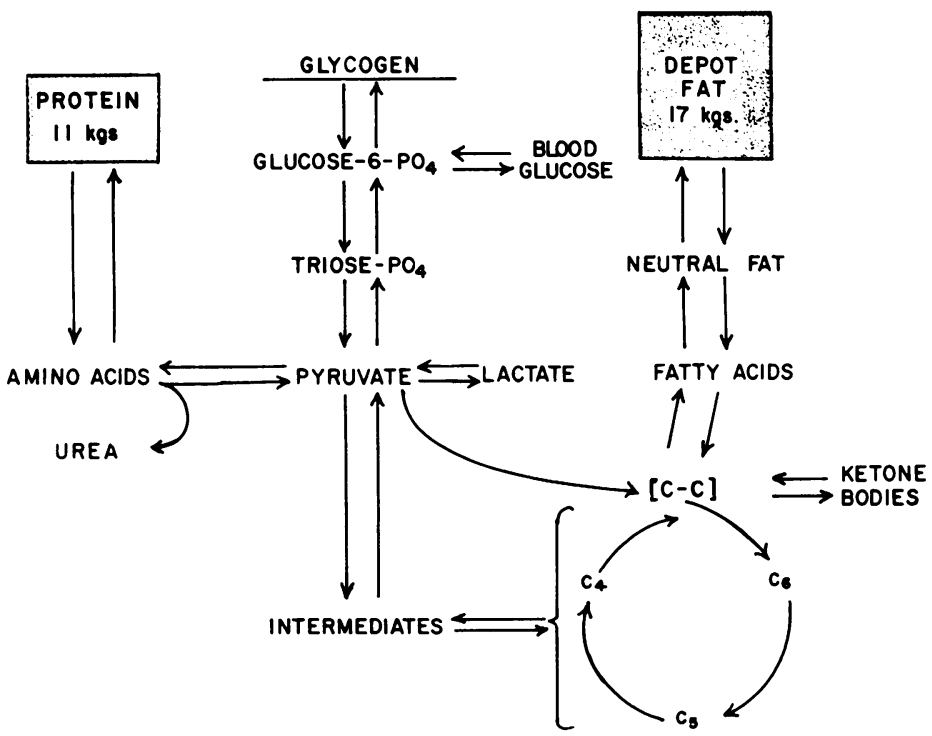

Fig. 6 An abbreviated diagram of the major pathways of intermediary metabolism which interconnect the three foodstuffs. See text for discussion of nitrogen loss (largely urea) after injury which is probably more related to mechanisms of gluconeogenesis than to the total demands for two-carbon fuel. where the nitrogen excretion per day is signi? ficantly increased. Thus, it seems that the nitrogen loss after injury must be occurring for reasons other than merely to provide extræ్ calories.

Our findings are in agreement with those of many other investigators who have noted that the rate of weight loss tends to parallel the extent of negative nitrogen balance. The apparent correla tion between weight loss and nitrogen loss can b explained partly on the basis of both the amounf of tissue used for fuel and the proportion of fat t $\delta^{\circ}$ lean tissue in the mixture. Fat is an anhydrous form of fuel with approximately $9 \mathrm{Cal} / \mathrm{g}$, while lean tissue has only approximately $1 \mathrm{Cal} / \mathrm{g}^{\mathrm{N}}$ (Kinney, 1959). This is because body protein exists in the body with approximately 3 parts of water, hence the $4 \mathrm{Cal} / \mathrm{g}$ of dry protein becomes $1 \mathrm{Cal} / \mathrm{g}$ of hydrated lean tissue when body protein is degraded following injury. Therefore, the weight loss associated with major injury or sepsis wiff have a relatively high proportion of hydrated lean tissue in the fuel mixture when considered by weight, whereas, when considered by calorie contribution, the hydrated lean tissue contributiof is only 12 to $22 \%$ of the entire resting calorie expenditure. Thus, the extreme weight loss of injury and sepsis is not due to the huge needs foo fuel in the metabolic furnace, but rather the body is meeting modest increases in energy demando with a low energy fuel that requires more fuew (and hence has a faster weight loss) to meet whate ever calorie deficit exists.

The idea that body protein is the major, of even a good, source of calories whenever the bod $\vec{\Phi}$ is faced with large increases in resting metabolisn following injury is not correct. Hence, explanat tions for the nitrogen loss after injury must be sought in alterations of intermediary metabolio pathways other than the final fuel mixture for oxidation.

\section{Intermediary Metabolism after Injury}

The pathways of intermediary metabolism bes tween the content of the three major foodstuffs i the adult male body are shown in abbreviated form in Figure 6. From the previous discussion it appears that the tricarboxylic acid cycle, shown in the lower right corner of the diagram, has onl modest increases in its need for two-carbon fuef after injury and sepsis, and that protein or aming acid breakdown is a poor source of such fuel. Fan from adipose tissue stores appears to be mobilized and oxidized without difficulty to meet whatever demands occur for extra calories as a result of injury. Therefore, one is left with the question as to the meaning of the extra nitrogen excretion seef after injury and sepsis.

The pathways of intermediary metabolism is Fig. 6 are deliberately oversimplified to empha size that most amino acids yield carbohydrat 
intermediates or are 'glucogenic' on deamination. It appears that while fatty acids can provide twocarbon fragments readily for general tissue fuel, they cannot be used to provide a net gain of carbohydrate intermediates, glycogen, or circulating glucose (Coleman, 1969). Therefore, in an actual or threatened situation of energy deficit, fat stores can be drawn upon for calories, but protein represents the only sizeable reserve for carbohydrate intermediates-something which is also critical for survival.

The changes in carbohydrate metabolism in the later phases after injury are not as well delineated as in the shock phase before resuscitation. Several investigators have shown that there is a tendency toward a diabetic-like glucose tolerance curve following elective operation (Hayes and Brandt, 1952 ) and that this is more marked after severe injury (Howard, 1955). This tendency toward hyperglycaemia and glucose intolerance during convalescence following injury has resulted in such terms as 'traumatic diabetes' (Thomsen, 1938) and 'diabetes of injury' (Drucker, Miller, Craig, Jeffries, Levy, and Abbott, 1953). This term suggests a relative or absolute lack of insulin activity and presumably a decrease in the levels of blood pyruvate and lactate after injury (Drucker, Craig, Hubay, Davis, and Woodward, 1961). The work of Drucker and his associates (Drucker, Craig, Kingsbury, Hofmann, and Woodward, 1962) has suggested a partial block in the pathways leading from pyruvate to two carbon fragments during the later phases of convalescence as well as the evidence for such changes during the shock phase.

The role of glucose metabolism in injury is further confused by the growing recognition of a syndrome first reported by Evans and coworkers (Evans and Butterfield, 1951) in occasional burn patients without any diabetic history, who developed unexpected lethargy and coma and were found to have marked hyperglycaemia without acidosis. During the past decade there has been growing awareness that lethargy, coma, and even death may occur occasionally in diabetic patients without explanation and has been given the name 'non-ketotic, hyperosmolar coma' (Ashworth, Sacks, Williams, and Byrne, 1968). One explanation has been that a sudden increase in circulating corticosteroids could inhibit the action of insulin, but most of the recorded cases have not been on steroid therapy. There appears to be an increasing incidence of this syndrome in acute surgical patients, when receiving large amounts of intravenous glucose.

The evidence for the idea that injury inhibits the oxidation of glucose has been indirect in man or limited to special circumstances in animal or tissue studies. Tracer studies with ${ }^{14} \mathrm{C}$-glucose have been employed with a mathematical model developed by Dr Jordan Spencer to relate blood and breath specific activities and the rate of $\mathrm{CO}_{2}$ production to the rate of glucose turnover and oxidation in surgical patients (Spencer, Long and Kinney, 1970). To date, 35 glucose runs have been made, including 14 volunteers (Long, Spencer, Kinney, and Geiger, 1970a) or patients undergoing elective surgery. The studies have demonstrated that glucose oxidation is essentially unchanged in minor degrees of trauma which may be expected to reduce glucose tolerance and perhaps increase the resting level of blood sugar. However, in the critically ill patient with a stable circulation and significant hyperglycaemia, our measurements indicate that such a patient has some increase in glucose oxidation as well as an increased glucose turnover in the bloodstream (Long, Spencer, Kinney, and Geiger, 1970b). We have also demonstrated that the hepatic manufacture and release into the bloodstream of new glucose, which is normally inhibited by the administration of approximately $6 \mathrm{~g}$ of glucose per hour intravenously, is no longer inhibited by the administration of this amount of glucose to the patient after major injury. The alteration in the control system by which the liver ceases to turn off this process for glucose manufacture is of both theoretical and practical interest, and is a subject of continuing study.

At the present time, neither the utilization of fat nor the breakdown of hydrated lean tissue with excretion of the associated water and nitrogen is adequate to explain the weight loss seen after injury. The additional reason for the rapid weight loss is that water in excess of tissue fuel is being excreted. This may be associated with the normal unloading of previously retained water, or to abnormal renal function. Another factor is the tendency seen in studies of starvation (Kekwick and Pawan, 1956) and paediatric nutritional studies (Holt, 1957) where the body excretes extra water for several days after shifting from a high carbohydrate to a high fat fuel mixture regardless of whether the fat is from the diet or from tissue stores as in starvation. The reverse phenomenon appears to occur when the body returns to a high carbohydrate diet. Analysis of the tissue composition of weight loss in patients following elective operation revealed that 35 to $45 \%$ of the weight loss was water in excess of that expected from the hydration of the measured protein breakdown (Kinney et al, 1968).

\section{References}

Artz, C. P., and Reiss, E. (1957). The Treatment of Burns. Saunders, Philadelphia.

Ashworth, C. J., Jr, Sacks, Y., Williams, L. F., Jr, and Byrne, J. J. (1968). Hyperosmolar hyperglycemic non-ketotic coma: its importance in surgical problems. Ann. Surg., 167, 556560.

Baker, P. T. (1961). Human bone mineral variability and body composition estimates. In Techniques for Measuring Body Composition, edited by J. Brožek, and A. Henschel, p. 69. National Academy of Sciences, National Research Council, Washington, D.C.

Buskirk, E. R. (1961). Underwater weighing and body density: A review of procedures. In Techniques for Measuring Body Composition, edited by J. Brožek and A. Henschel, p. 90. National Academy of Sciences, National Research Council, Washington, D.C. 
Coleman, J. E. (1969). Metabolic interrelationships between carbohydrates, lipids and proteins. In Duncan's Diseases of Metabolism, Vol. 1, Genetics and Metabolism, 6th ed., edited by P. K. Bondy, and L. E. Rosenberg, pp. 89-198. Saunders, Philadelphia.

Cuthbertson, D. P. (1932). Observations on the disturbance of metabolism produced by injury to the limbs. Quart.J. Med., 1, 233-246

Cuthbertson, D. P. (1942). Post-shock metabolic response. Lancet, 1, 433-437.

Drucker, W. R., Craig, J. W., Hubay, C. A., Davis, J. H., and Woodward, H., Jr. (1961). The metabolic effects of trauma to denervated tissues in man. J. Trauma, 1, 306-321.

Drucker, W. R., Craig, J., Kingsbury, B., Hofmann, N., and Woodward, H. (1962). Citrate metabolism during surgery. Arch. Surg., 85, 557-563.

Drucker, W. R., Miller, M., Craig, J. W., Jeffries, W. M., Levey, S., and Abbott, W. E. (1953). A comparison of the effect of operation on glucose and fructose metabolism. Surg. Forum, 3, 548-555.

Duke, J. H., Jr., Jørgensen, S. B., Broell, J. R., Long, C. L., and Kinney, J. M., (1970). The contribution of protein to calorie expenditure following injury. Surgery, 68, 168174.

Evans, E. I., and Butterfield, W. J. H. (1951). The stress response in the severely burned. Ann. Surg., 134, 588-613.

Hayes, M. A., and Brandt, R. L. (1952). Carbohydrate metabolism in the immediate postoperative period. Surgery, 32, 819-827.

Holt, L. E., Jr. (1957). Dietary fat: its role in nutrition and human requirement. J. Amer. med. Ass., 164, 1890-1894.

Howard, J. M. (1955). Studies of the absorption and metabolism of glucose following injury. Ann. Surg., 141, 321-326.

Kekwick, A., and Pawan, G. L. S. (1956). Calorie intake in relation to body-w zight changes in the obese. Lancet, 2, 155-161.

Keys, A., Brožek, J., Henschel, A., Mickelsen, O., and Taylor, H. L. (1950). The Biology of Human Starvation. University of Minnesota Press, Minneapolis.

Kinney, J. M. (1959). Influence of intermediary metabolism on nitrogen balance and weight loss. Metabolism, 8, 809-826.

Kinney, J. M., Long, C. L., Gump, F. E., and Duke, J. H., Jr. (1968). Tissue composition of weight loss in surgical patients. I. Elective operation. Ann. Surg., 168, 459-474.

Kinney, J. M., Morgan, A. P., Domingues, F. J., and Gildner, K. J. (1964). A method for continuous measurement of gas exchange and expired radioactivity in acutely ill patients. Metabolism, 13, 205-211.
Krieger, M. (1920). Ueber die Atrophie de menschlichen Organe) bei Inanition. $Z$. angew. Anat. konstiturionsl., 7, 78-134.

Long, C. L., Kopp, K., and Kinney, J. M. (1969). Energy demands during ambulation in surgical convalescence. Surg. Forum 20, 93-94.

Long, C. L., Spencer, J. L., Kinney, J. M., and Geiger, J. (1970aß口 Effect of glucose infusions on carbohydrate metabolism in normal man. In preparation.

Long, C. L., Spencer, J. L., Kinney, J. M., and Geiger, J. (1970b) Glucose metabolism in man: effect of elective operation and major injury. In preparation.

Lusk, G. (1928). The Elements of the Science of Nutrition, 4th ec를 Saunders, Philadelphia.

Moore, F. D. (1946). Determination of total body water and solid with isotopes. Science, 104, 157-160.

Moore, F. D. (1953). Bodily changes in surgical convalescence. p The normal sequence: observations and interpretations. Ann. Surg., 137, 289-315.

Moore, F. D., and Ball, M. R. (1952). The Metabolic Response to Surgery. Thomas, Springfield, Illinois.

Moore, F. D., McMurrey, J. D., Parker, H. V., and Magnus $\vec{\omega}$ I. C. (1956). Body composition. Total body water and electrolytes: intravascular and extravascular phase vo umes. Metabolism, 5, 447-467.

Moore, F. D., Olesen, K. H., McMurrey, J. D., Parker, H. V is Ball, M. R., and Boyden, C. M. (1963). The Body Cell Mas $\$$ and Its Supporting Environment. Saunders, Philadelphia. :

Pace, N., and Rathbun, E. N. (1945). Studies on body composition III. The body water and chemically combined nitrogeer content in relation to fat content. J. biol. Chem., 158 685-691.

Moore, F. D. (1959). Metabolic Care of the Surgical Patiente Saunders, Philadelphia.

Siri, W. E. (1961). Body volume measurement by gas diiution. Iญิ Techniques for Measiuring Body Composition, edited by Brožek and A. Henschel, p. 108. National Academy of Sciences, National Research Council, Washington, D.C. $<$

Spencer, J. L., Long, C. L., and Kinney, J. M. (1970). A mathematical model for glucose metabolism in man. In prepara tion.

Studley, H. O. (1936). Percentage of weight loss; a basic indicator of surgical risk in patients with chronic peptic ulcer. Amer. med. Ass., 106, 458-460.

Thomsen, V. (1938). Studies of trauma and carbohydrate metabolism with special reference to the existence on traumatic diabetes. Acta med. scand., Suppl. 91. 